\title{
Graphite Flake Size Effects to Thermal Durability of Automobile Flywheel Under Forced Slippage
}

\author{
Mehmet Onur Genç, Çağlar İmer \\ Valeo Automotive \\ Bursa, Turkey \\ mehmet-onur.genc@valeo.com; caglar.imer@valeo.com
}

\begin{abstract}
The objective of this study is to investigate thermal durability of grey cast iron GJL250 material flywheel based on casting graphite flake size under abusive and unusual driving condition which causes forced slippage. In daily routine, drivers may make half press of clutch pedal and switch the gear out of sequence during long traffic condition. This case leads to slippage between flywheel and clutch that causes energy dissipation in clutch house. During slippage, thermal load on flywheel increases and when it reaches critical level this may cause thermal cracks on flywheel. In this study, graphite flake size effects on thermal durability were investigated. In order to simulate daily abusive usage, flywheels which have different graphite flake type and size were subjected to forced slippage test at the test bench which simulates the abusive usage on the car. The findings of this study is different size of graphite flake types on flywheel directly effects the thermal performance of material and may cause prominent cracks during over dissipated energy occurrence. At the end of the forced slippage test, the cast iron which has higher graphite size completed the test without crack, whereas prominent cracks were observed on the casting which has smaller laminar graphite size.
\end{abstract}

Keywords: dissipated energy, clutch, slippage, cast iron, graphite flake, automobile flywheel

\section{Introduction}

Flywheel (1) is the safety product in powertrain system with high inertia and ability of high thermal capacity. Flywheels are bolted to engine crankshaft and clutch cover assembly(3). During engagement, the disc (2) is clamped between the pressure plate and flywheel, resulting in torque transfer from engine transmission.

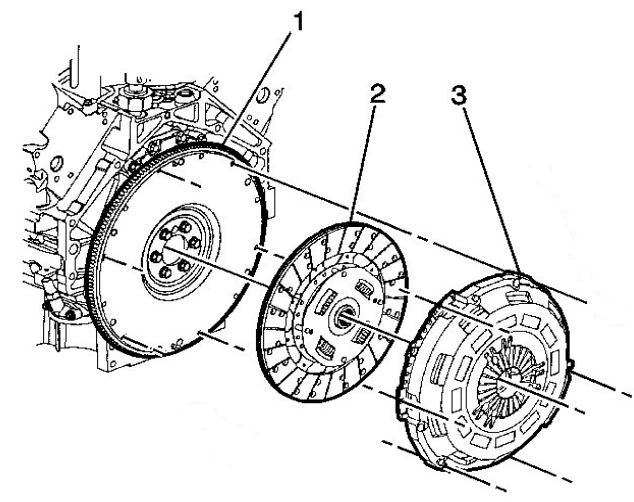

Fig. 1: Flywheel and Clutch.

Under driving conditions between engine and transmission relative motions occur due to dynamic variables such as gear switch, engine break, speed slow down.. etc. Clutch disc is the durable structure that provides torque transmission through friction between flywheel and pressure plate, interrupts the torque transmissibility by means of the force that implemented towards to cover assembly diaphragm springs. Relative motions between flywheel and clutch disc cause

ICMIE 121-1 
slippage that leads to dissipated energy. During slippage, thermal load on flywheel increases and this may cause thermal cracks on flywheel. Thermal cracks may extend especially at high revolution that may results in completely breakage of flywheel.

Flywheel material is chosen generally grey cast iron which is a type of cast iron that has a graphite microstructure. It is used for housings where the stiffness of the component is more important than its tensile strength, such as internal combustion engine cylinder blocks, pump housings, clutch plates, flywheels. Several groups exist according to material properties in grey cast iron. Grey cast iron has good casting properties, high machinability, high thermal conductivity, high resistance against corrosion, good wear resistance as well as good vibration damping. These are the reasons Graphite flake lengths can be divided several groups that classified according to flake characteristics. Flake characteristic have play major role in terms of thermal durability on the products. Graphite flake characteristics can be effected by casting process and material characterization such as cooling time, casting type, carbon equivalent...etc.

Pevec et al. (2014) investigated the grey cast iron (GJL250) behaviours for automotive brake discs under operational temperatures up to $700 \mathrm{C}$. In this study material mechanical properties were studied by making mechanical and fatigue analysis. It was found that up to $500 \mathrm{C}^{\circ}$ operational temperature cast iron mechanical properties too low compare to $500 \mathrm{C}$ and above values. . Gray cast irons maintain their mechanical properties up to approximately $500^{\circ} \mathrm{C}$. Above $500^{\circ} \mathrm{C}$ the mechanical properties drop quickly [1]. Behnam et al. (2010) investigated the grey cast iron cooling process effects on graphite flakes and casting hardness. Several tests are performed to indicate the mechanical and microstructural properties. Results are show that cooling rate has big effects on graphite flakes that longer cooling process provides long graphite flakes [2]. Bertolino et al. (2006) Investigated in their study the effects of graphite lamel size on fracture and endurance of casting. Trials done with different size of graphite flakes and fracture behaviours investigated. The effect of some geometric variables on a grey cast iron fracture toughness was analysed [3]. Hecht et al. (1999) In their study made comparison between graphite flakes and thermal diffusivity, it was found that higher lamel size shows higher thermal diffusivity. Thermal diffusivity of automotive grade gray cast iron has been measured as a function of graphite flake morphology, chemical composition and temperature. In their study graphite flakes are measured and classified according to their size [4] .

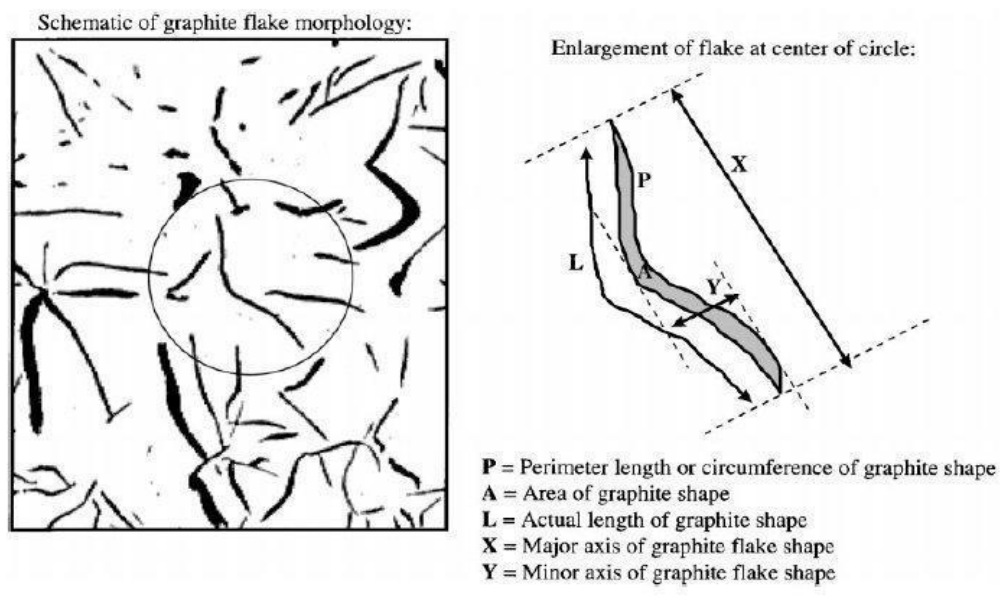

Fig. 2: Characterization of graphite flake morphology (Hecht et al.).

Ohser et al. (2003) In their study made classification for types of graphite and according to microstructure analysis made further classification. In the study new method for classification of lamellar graphite are investigated [5] . Kılıç et al. (2016) Investigated the compactness of the clutch pressure plate effects on heat dissipation energy in clutch house. In the study finite element method was used to investigate the effect of clutch pressure plate compactness on the heat dissipation [6]. Sahu et al. (2014) investigated that the cooling process effects on graphite flakes size. In the study it was found that rapid cooling rate leads to smaller graphite size. Further investigation revealed the several effects of smaller lamel size on the durability of casting. According to results flake sizes effects the some properties of material such as tensile strength, hardness and damping capacity of cast iron [7].

ICMIE 121-2 
In this study graphite flake size effects to thermal durability of automobile flywheel is experimentally investigated with forced slip test. Grey cast iron material is widely used for vehicle components owing to its mechanical proporties under dynamic conditions. This paper makes experimental approach the thermal durability of flywheels using with forced slip test which simulates the abusive driving condition.

\section{Material and Method}

The dissipated energy and loss of friction materials increases with slipping duration. Under normal working conditions amount of kinetic energy converted into heat that leads temperature increasing. Repeated clutch engagement increases the temperature in clutch house. In addition, the gray cast irons have very high thermal conductivity due to graphite flakes. The heat also can be dissipated very fast from the contact by the gray cast iron. The equations of the thermal loads, total energy dissipated and relative velocity between contact surfaces are presented. The temperature distributions and the heat generation of friction clutch are considered the thermal stresses and rate of wear due to the slipping during engagement. Friction coefficient between metal components (pressure plate and flywheel) and clutch disc facings decreases by the time temperature reaches a critical level $\left(300-400{ }^{\circ} \mathrm{C}\right)$ that leads to loss of torque transmission. Torque transmission $T(t)[\mathrm{Nm}]$ is proportional to clamp load $F[\mathrm{~N}]$, friction coefficient $\mu$, facing number $\mathrm{N}$ and mean radius $\mathrm{Rm}$.

$$
T=N * \mu * F * R m
$$

Generated heat flux during slippage phase is distributed between flywheel and clutch based on their thermal diffusivity. The heat is transferred by conduction between the solid parts depending on their specific heat $C_{p}[\mathrm{~J} / \mathrm{kgK}]$ and mass $m[\mathrm{~kg}]$.

$$
\mathrm{Q}=\mathrm{M} * \mathrm{C}_{\mathrm{p}} * \Delta \mathrm{T}
$$

\subsection{Forced Slip Test}

Minimizing energy loss is the important goal in the internal combustion engines. Energy dissipation within the clutch occurs during the engaging operation as a function of transmitted torque $\mathrm{T}$ and rotational speed difference between flywheel $\mathrm{W}_{\text {flywheel }}$ and $\mathrm{W}_{\text {clutch disc facing. }}$.

$$
\mathrm{P}_{(\mathrm{t})}=\mathrm{T}_{(\mathrm{t})} *\left(\mathrm{~W}_{\text {flywheel }(\mathrm{t})}-\mathrm{W}_{\text {clutch disc facing }(\mathrm{t})}\right) * \mathrm{dt}
$$

Forced slip test is aim to find material and design endurance under abusive usage for vehicles. Test is performed according to procedures in order to verification of mechanical strength of flywheel and clutch pressure plates submitted to continuous extreme heat flow, generated by clutch slippage. Test bench is adapted to manage test by torque regulation at constant speed. The torque is regulated to max engine torque (Cmax) and the speed is constant at max engine torque. It consists of 2 phase which are mainly to provide system approach in terms of thermal durability. During $1_{\text {st }}$ phase flywheel and clutch are submitted to vehicle max torque by adjusting on test bench under rotation which indicated at maximum torque on real vehicle. While cover assembly and flywheel rotate together with adjusted RPM, clutch disc is subjected to torsion resistance by the torque machine. Thus, slippage occurred due to frictional phenomenon bilaterally between flywheel-disc and cover assembly-disc. Increasing slippage within time leads to heat increasing by converting kinetic energy to heat. This energy presented dissipated energy which has effects on the components of the clutch and flywheel and so on powertrain system.

Figure 3 shows that during test rotation is given at constant speed and within time by the heat increasing clamp load will decrease gradually and towards the end of first phase disc friction capacity will reached the wear capacity. Test is stops when the transmitted torque reaches zero.

ICMIE 121-3 


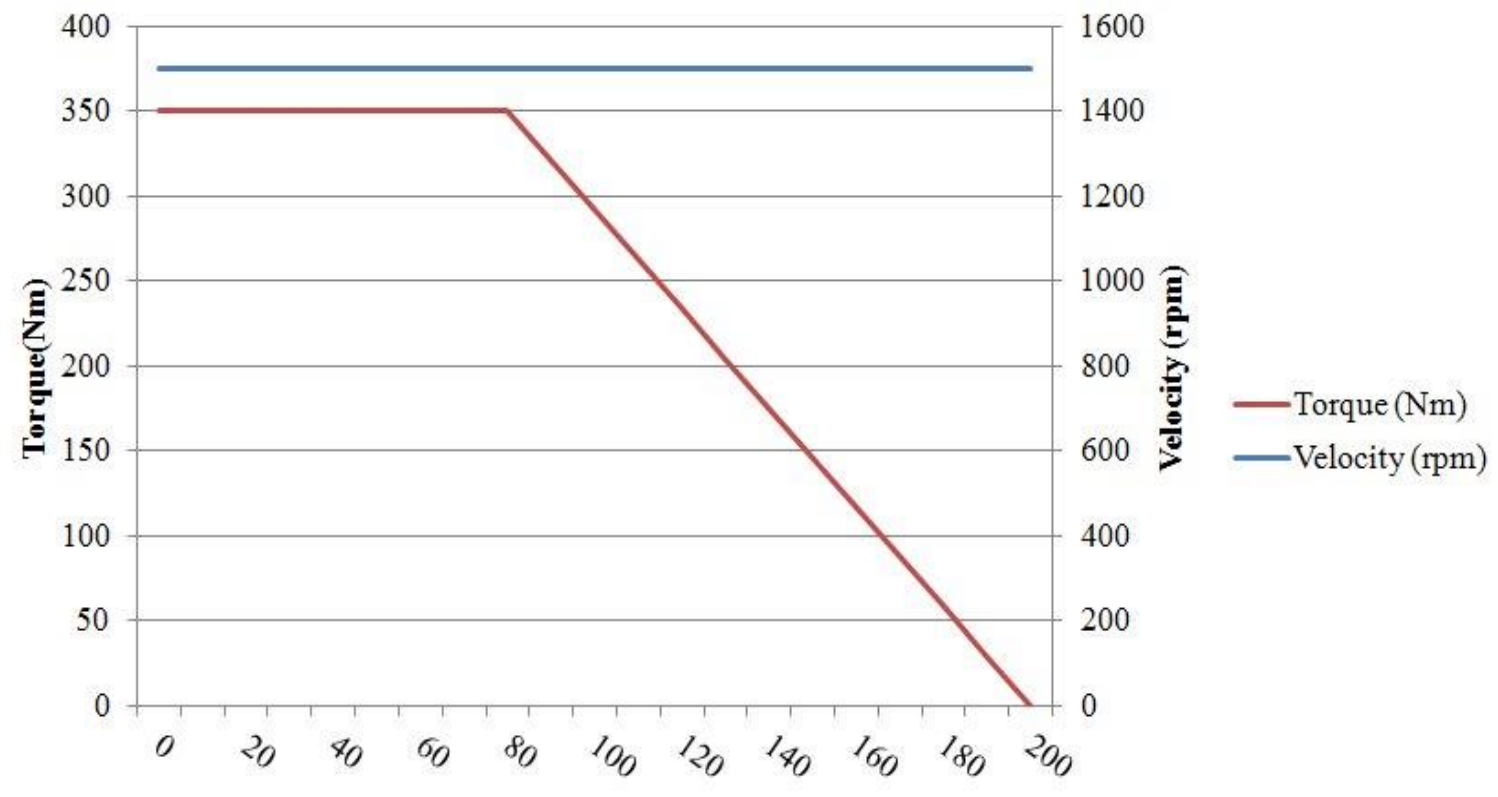

Time (s)

Fig. 3: Linearized phenomenon of forced slippage.

\subsection{Graphite Flake Characterization}
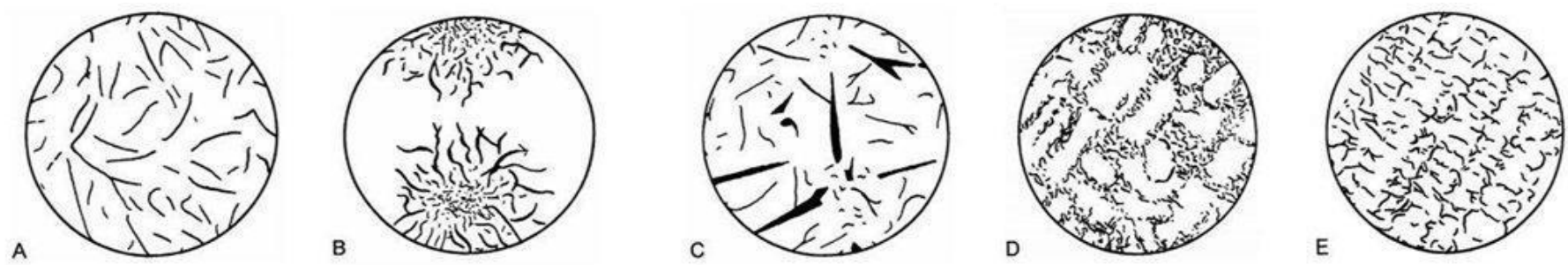

Fig. 4: Graphite flake types.

Gray irons typically have low ductility and moderate strength, but they have high thermal conductivity and excellent vibration damping properties. Type A graphite flake structures are generally the preferred structures than the other types of flakes. High wear resistance, high heat absorption capability to absorb braking energy, high thermal conductivity to transport frictional heat away from friction surfaces, high vibration damping capacity to minimize vibration, high degree of corrosion resistance, good machinability. The cooling rate, like the chemical composition,can significantly influence the structure and therefore the mechanical properties. Increasing the cooling rate will both graphite size and matrix structure increase strength and hardness.

\section{Analysis and Discussions}

In this section microstructure analysis are analysed and these parts are subjected to forced slip test. First step, grey casting samples from different sources are given to material content analysis. Table 1. shows the material contents;

Table 1: Material contents of tested parts.

ICMIE 121-4 


\begin{tabular}{|c|c|c|c|c|c|c|c|c|c|c|c|c|c|c|c|}
\hline & \multicolumn{15}{|c|}{ Material Inspection (GJL 250) } \\
\hline $\begin{array}{c}\text { Batch } \\
\text { Information }\end{array}$ & $\mathbf{C}$ & $\mathbf{S i}$ & $\mathbf{S}$ & $\mathbf{P}$ & Mn & $\mathbf{N i}$ & $\mathrm{Cr}$ & Mo & $\mathbf{C u}$ & Sn & Al & Mg & Ceq & $\begin{array}{c}\text { Tensile Strength } \\
\text { (MPa) }\end{array}$ & $\begin{array}{c}\text { Hardness } \\
\text { (HB) }\end{array}$ \\
\hline $\begin{array}{c}\text { Cast Iron } \\
\text { Batch 1-higher } \\
\text { flakes }\end{array}$ & 3,38 & 2,26 & 0,096 & 0,045 & 0,98 & - & $\mathbf{0 , 4 2}$ & - & $\mathbf{0 , 5 9}$ & $\mathbf{0 , 0 3}$ & - & - & 4,14 & 274 & 223 \\
\hline $\begin{array}{c}\text { Cast Iron } \\
\text { Batch 2-lower } \\
\text { flakes }\end{array}$ & 3,32 & 2,19 & $\mathbf{0 , 0 7}$ & 0,06 & $\mathbf{0 , 8 4}$ & $\mathbf{0 , 0 4}$ & 0,47 & - & 0,6 & $\mathbf{0 , 0 3}$ & - & - & 4,11 & 285 & 229 \\
\hline
\end{tabular}

In the table it is seen that both casting material contents are close to each other and can be neglected in terms of key important values such as carbon (C), carbon equilavent (Ceq)...etc. Carbon equilavent (Ceq) has big effect on creation of graphite flake length in addition to casting process such as cooling rate. Two sources were analysed to define graphite lamel structure. The outputs shown in the below figure 5;

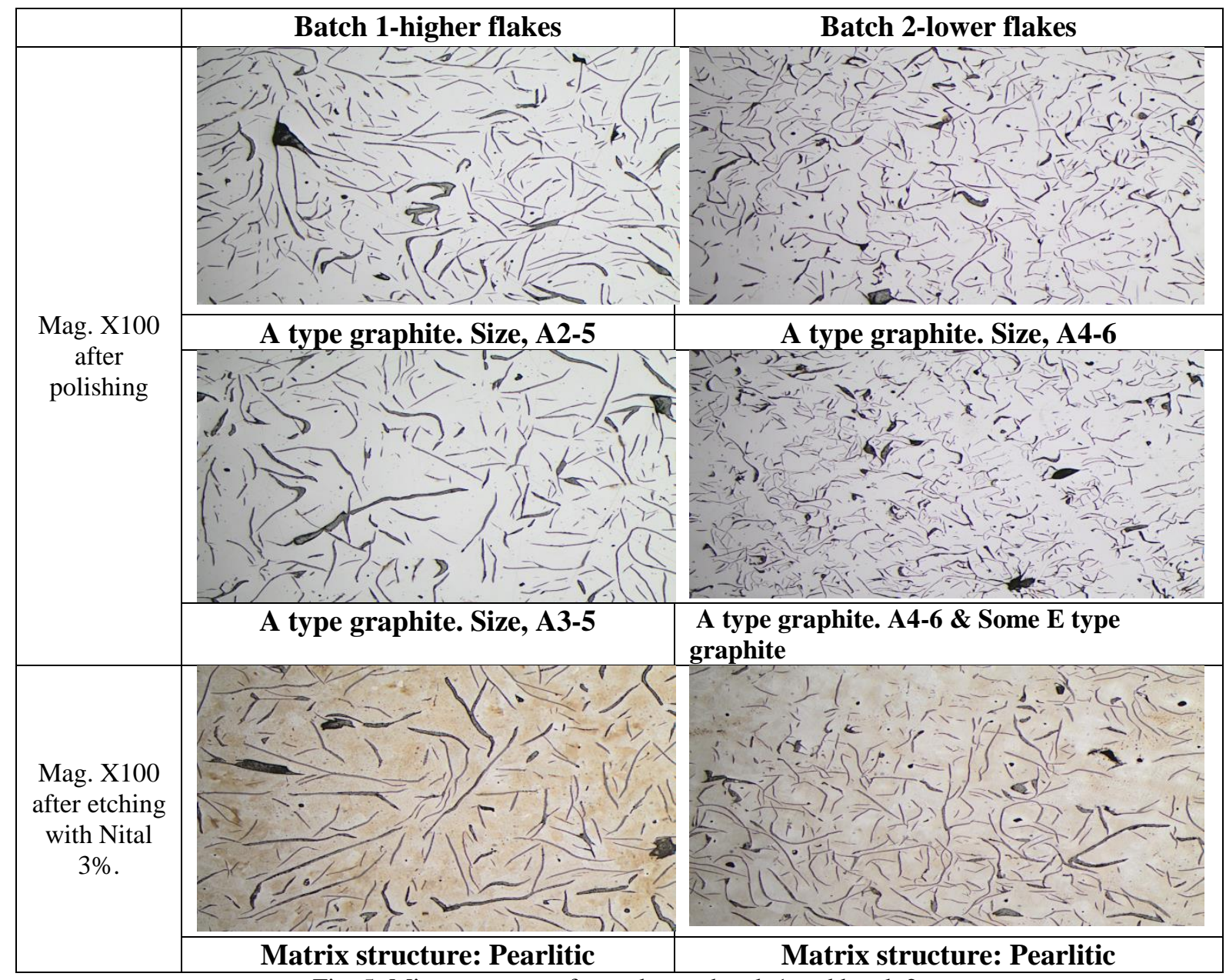

Fig. 5: Microstructure of tested parts batch 1 and batch 2 .

After microstructure analysis both casting have different types of lamel graphite flake length subjected to forced slip test. Both casting which have same designed are tested with same clutch kits that using in same vehicle. Before the test, machine is regulated the specific conditions specified to vehicle. As described in material and method 2.1 during test constant RPM is given to test machine at vehicle maximum torque level. Within time due to dissipated energy, heat 
increasing on disc facing causes worn out and clamp load decreases due to slippage. Facing temperature expected to reach $300 \mathrm{C}^{\circ}$ in the slippage phase and until total worn capacity completed for the clutch disc torque level is expected to stay at vehicle maximum torque level.

Batch 1 presents higher graphite flake size. Figure 6 shows the outputs of the test. It is seen on the table that slippage duration takes 198 seconds and totally $6900 \mathrm{Kj}$ dissipated energy occurred.

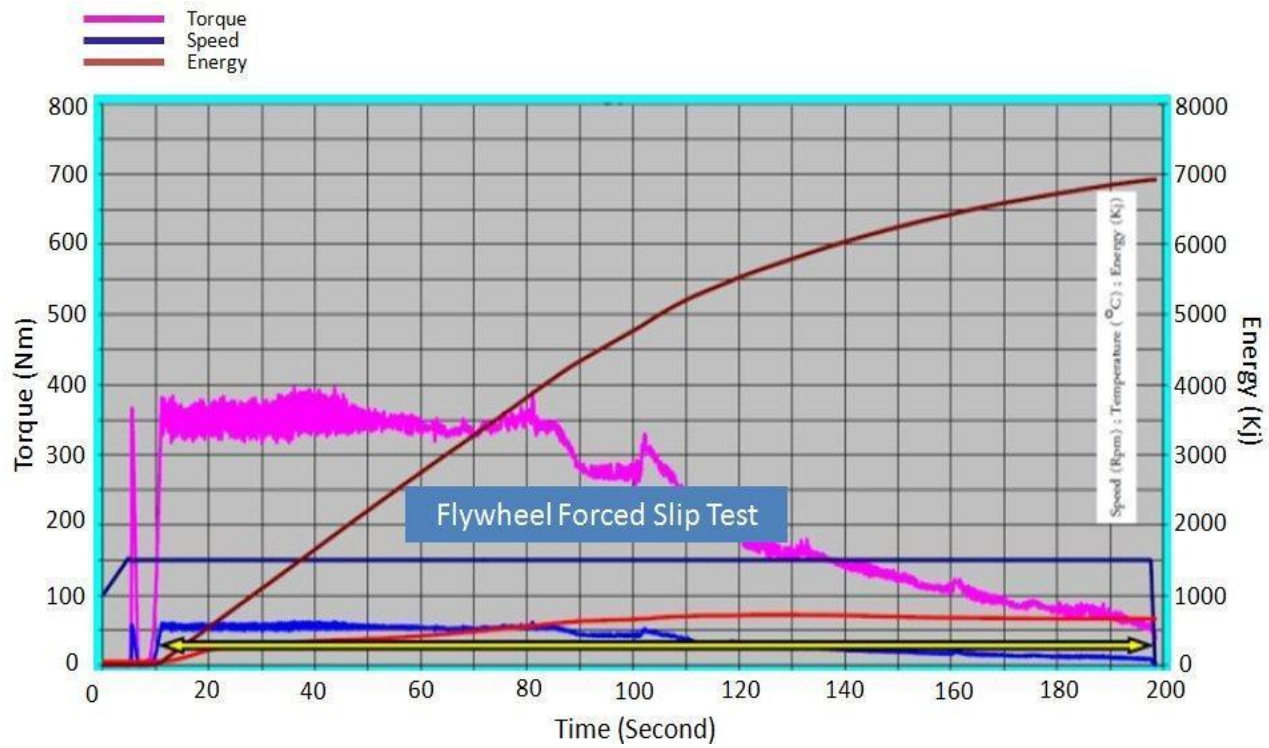

Fig. 6: Forced slip test graphic for batch 1.

Batch 2 presents lower graphite flake size, figure 7 shows the outputs of the test. It is seen on the table that slippage duration takes 180 seconds and totally $6600 \mathrm{Kj}$ dissipated energy occurred.

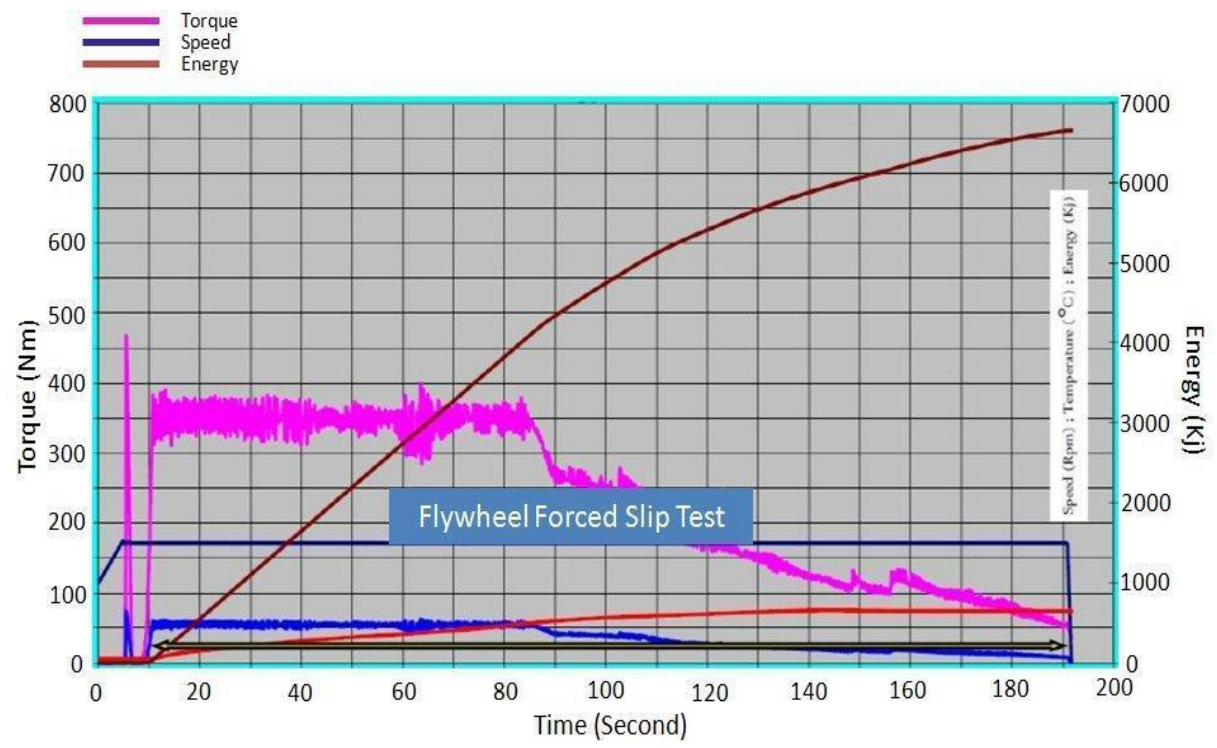

Fig. 7: Forced slip test graphic for batch 2. 


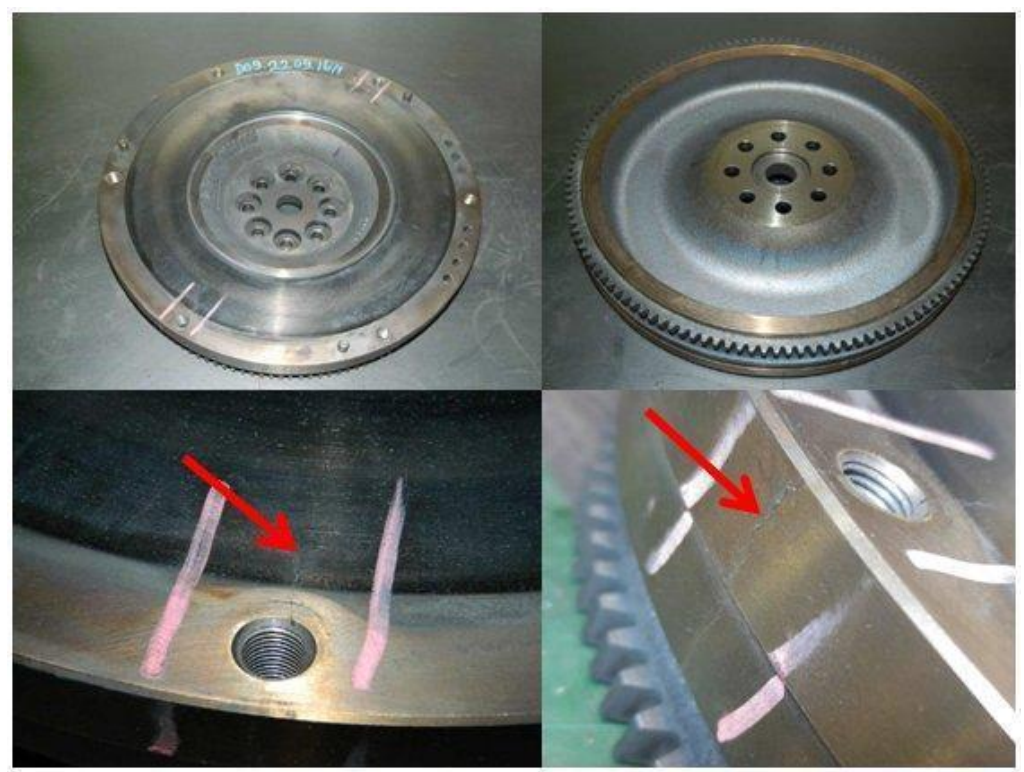

Fig. 8: Cracks after test for batch 2 lower graphite flakes.

Expert analysis after test shows that cracks occured towards to the screw hole region. This case describes that severe section transitions on the design such as paths and fillets effected by thermal flow and cause cracks shows in figure 8 .

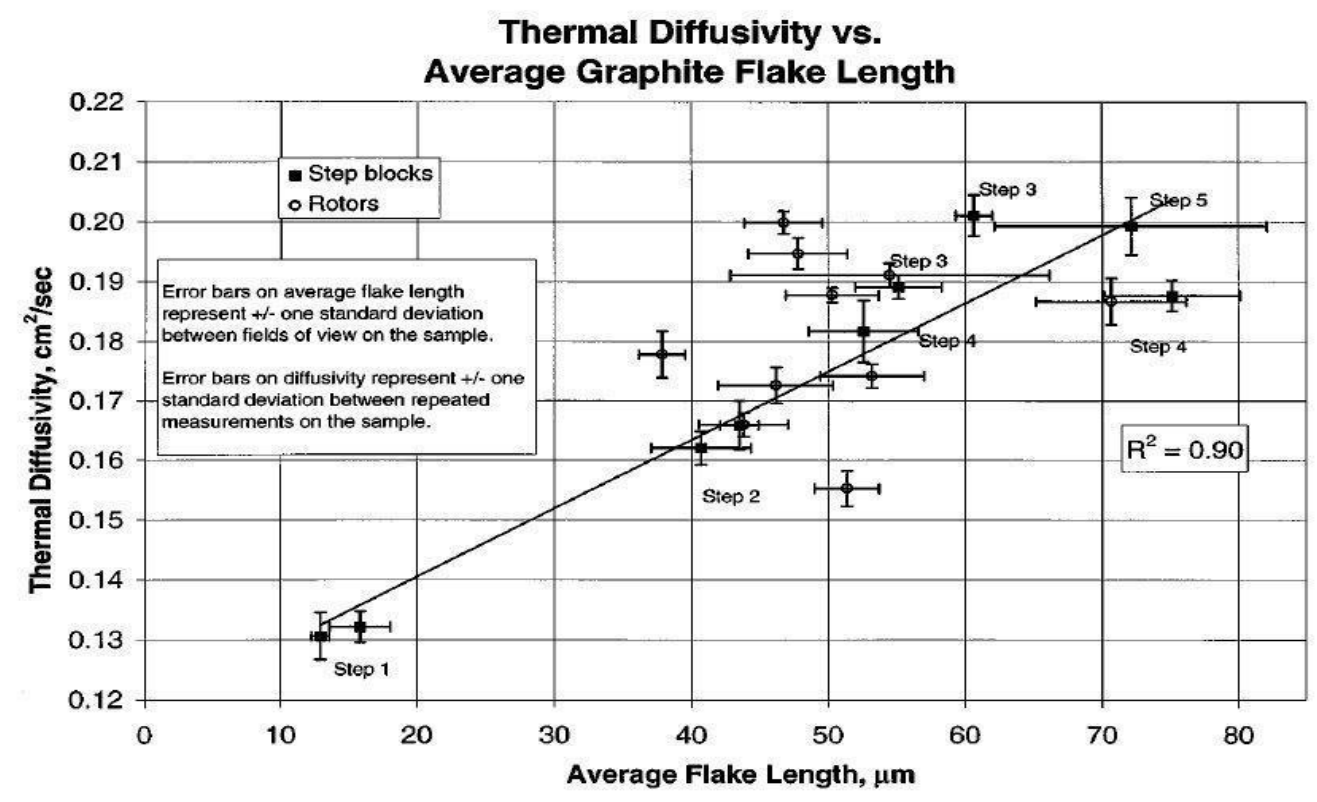

Fig. 9: Thermal diffusivity vs. average graphite flake length (Hecht et al.).

It is directly proportional with the study of Hecht et al. shows on Figure 9. Hecht et al. in their study investigated the thermal diffusivity variation with flake length. Step block castings in different size block steps subjected to different cooling rate and various flake length is obtained. Flake length is classified according to size with image analysis and thermal diffusivity is measured at room and elevated temperatures by means of flash technique. It was found in the study that flake length size directly effects the thermal durability of the grey cast iron. Higher flake length provides higher thermal diffusivity that increase thermal durability (Figure 9). 


\section{Conclusion}

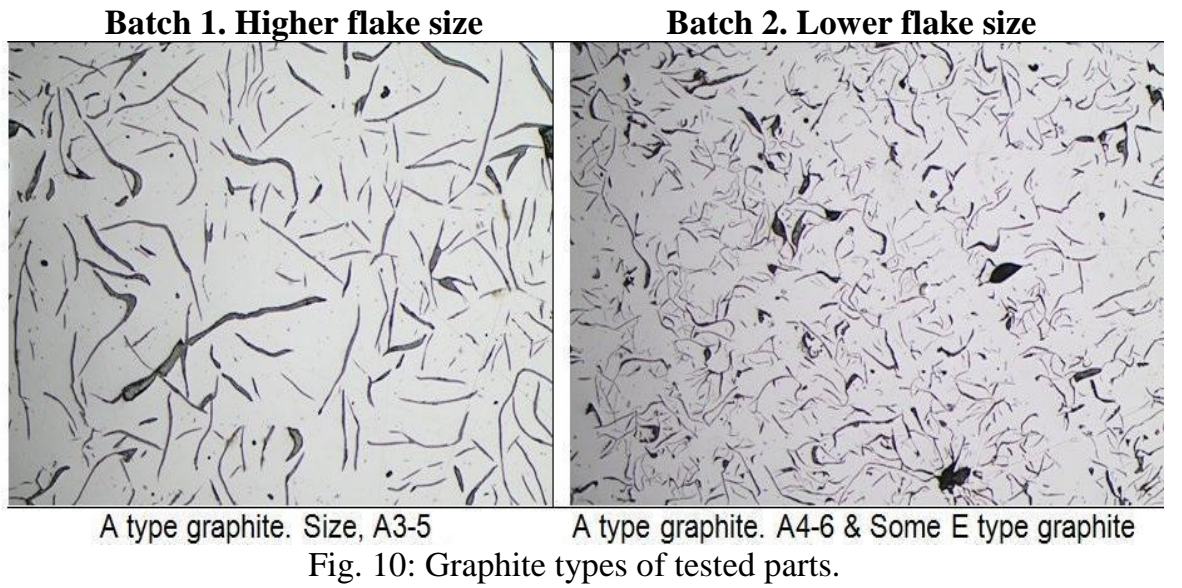

In this study the automobile flywheel was investigated based on the thermal durability by classification of graphite flake type. In order to make detailed analysis, two grey casting have different types of graphite flakes were subjected to forced slip test. Results of the study shows that graphite flake size have major effects on thermal durability of the material exposed to slippage in powertrain systems on vehicles. It is releaved that higher graphite flake provides significant thermal endurance owing to its long size. In order to make comparison two different graphite type of flywheel from different sources were tested under the forced slippage condition. At the end of the test it was seen A2-A4 type of flakes show high thermal endurance and no any cracks occured on the tested flywheel, whereas the small size graphite A4-A6 and E types present lower thermal endurance that cracks and breaks occurred near the screw location on flywheel.

\section{References}

[1] M. Pevec, G. Oder, I. Potrc, M. Šraml, "Elevated temperature low cycle fatigue of grey cast iron used for automotive brake discs," Engineering Failure Analysis, vol. 42, pp. 221-230, 2014.

[2] M. M. J. Behnama, P. Davamia, N. Varahram, "Effect of cooling rate on microstructure and mechanical properties of gray cast iron," Materials Science and Engineering A, vol. 528, pp. 583-588, 2010.

[3] G. Bertolino, J. E. Perez-Ipina, "Geometrical effects on lamellar grey cast iron fracture toughness," Journal of Materials Processing Technology, vol. 179, pp. 202-206, 2006.

[4] R. L. Hecht, R. B. Dinwiddie, H. Wang, "The effect of graphite flake morphology on the thermal diffusivity of gray cast irons used for automotive brake discs," Journal of Materials Science, vol. 34, pp. 4775-4781, 1999.

[5] J. Ohser, K. Sandau, W. Stets, W. Gerber, "Image Analytical Characterization of Graphite in Grey Cast Iron and Classification of Lamellar Arrangement," Praktische Metallographie, vol. 40, no. 9, pp. 454-473, 2003.

[6] M. Kılıç, T. Çakmak, G. Sevilgen, "Clutch Pressure Plate Effect on the Clutch System Heat Dissipation," 12th International Conference on Heat Transfer, Fluid Mechanics and Thermodynamics, pp. 438-444, 2016.

[7] S. Sahu, M. N. Bhat, A. Kumar, A. Pratik, A. Kumar, "Effect of Section Thickness On The Microstructure And Hardness Of Gray Cast Iron," International Journal of Engineering Research \& Technology (IJERT), ISSN: 22780181, vol. 3, no. 7, pp 35-40, 2014.

[8] A. Vadiraj, "Engagement characteristics of a friction pad for commercial vehicle clutch system," Indian Academy of Sciences, vol. 35, no. 5, pp. 585-595, 2010.

[9] R. P. Yadav, "Design and Analysis of Automotive Powertrain Using Static, Model, Thermal and Transient Structure Analysis Techniques," International Journal of Science and Research, vol. 4, ISSN (Online): 2319-7064, pp. 131$137,2015$. 